\title{
Empowered Bleeders and Cranky Menstruators: Menstrual Positivity and the "Liberated" Era of New Menstrual Product Advertisements
}

\author{
Ela Przybylo and Breanne Fabs
}

\section{INTRODUCTION}

Menstrual product advertisements (Mpads), since their early years, have been reliant on misogynist discourses around menstruation, portraying menstruation as shameful and unmentionable, vaginas themselves are the source of squalor and filth, and menstrual blood as requiring containment, concealment, and sanitization through euphemism and blue-liquid advertising (Saz-Rubio and Pennock-Speck 2009; Kissling 2002; Thornton 2013). Grounded in representations of menstruating bodies on white, cisgenderist, ableist, fatphobic, and heteronormative terms, menstrual product advertising has a long history that spans from the early commercialization of menstrual products in the 1920s and across the mediums of print (since 1921), television (since 1970), and the internet. In recent years, in the context of increasing menstrual activism, fights for menstrual justice and access to menstrual products, and feminist efforts at shifting discourses around what it means to bleed, it seems that a "new" era of Mpads is surfacing-one more willing to both poke fun at histories of menstrual shame and to envision bleeding on empowering and glittery terms.

Yet as we explore in this chapter, while new menstrual product advertising certainly does envision menstrual bleeding on celebratory and liberated terms, major brands such as Always, $\mathrm{U}$ by Kotex, and Libresse/Bodyform do so by co-opting feminist discourses and the energies of menstrual activism. Continuing to rely on narrow understandings of menstruating bodies as 
feminine and female bodies, these ads tend to push able-bodied fitness as well as obligatory positivity onto those who menstruate, while foregoing questions of menstrual product access and the more painful aspects of bleeding. Swept up by the flows of menstrual positivity, and distancing themselves from previous commitments to shaming menstruators, companies such as Always, $U$ by Kotex, and Libresse/Bodyform seem newly unable to come to terms with the fact that "periods don't have glitter in them" (as a HelloFlo ad we later examine jokingly proclaims) or that they are not by default empowering and fun.

In this chapter, we examine a series of new Mpads, including "Reality Check" by Kotex (2013), "First Moon Party" by HelloFlo (sponsored by U by Kotex 2014), "\#LikeAGirl" by Always (2014), and "Blood" by Bodyform UK (2016). We have selected these ads in particular because they are produced by large Western megacorporations that have historically relied on menstrual shaming even while also co-opting feminist efforts of menstrual and bodily positivity for profit. We thus argue that these Mpads co-opt feminist discourses and energies of body positivity and menstrual positivity toward pushing consumer capitalist goals of selling menstrual gear with an "empowered" message. Drawing on feminist menstrual scholarship, we argue that parallel to other co-optations of feminist self-love and body positivity rhetoric, menstrual positivity is thinned, whitened, and transformed when utilized toward the sale of menstrual gear. We argue that "positivity"-while an important starting point from which to undertake feminist menstrual activism, praxis, and theorizing-is easily co-optable within neoliberal marketing cultures. Acknowledging the importance of affirmative menstrual messaging, we nevertheless develop a "menstrual crankiness" that draws on positivity but also holds it critically at bay. Aligned with queer theoretical work on the political import of negative affects such as that of Sara Ahmed (2010), we agitate for the importance of menstrual crankiness in pushing at sexist and transphobic discourses around bodies and embodiment-arguing that menstrual crankiness is vital to thinking the material pains and pleasures of menstrual bleeding.

In thinking about the value of moving toward a crankier approach to the menstruating body as one that pushes beyond the framework of empowerment, we centralize recognition of pain, access, and justice. In short, we advocate a cranky menstrual experience as a way to embrace a more complete and justice-oriented perspective of menstruation attuned to the difficult aspects of bleeding. Menstrual justice, a riff on reproductive justice (Ross et al. 2016), in this sense includes thinking about menstruation, menstrual pain, and access to menstrual products intersectionally, and in dialogue with one's position in relation to power structures. Menstrual justice also includes seeing access to menstrual products, including pain control, as a human right as well as understanding menstrual pain as a form of chronic pain that necessitates proper access to care (Winkler and Roaf 2014; Kissling 2006, 126; Jones 2016; Przybylo and Fahs 2018). 
Notably, this orientation also extends to the language we use in this piece. As in our earlier piece on menstrual pain (Przybylo and Fahs 2018), we interchangeably move between using the language of women and the language of menstruators. This recognizes the value of expanding the circle of "who menstruates" beyond women and troubling binary generalizations that all women menstruate and all men do not while also recognizing the deeply misogynistic impulses of menstrual negativity and stigma. Further, while much of the language used by advertisers references the "feminine"-with, for example, "feminine hygiene," "feminine products," "feminine odor," and so onwe shift toward a language of "menstrual products" and "menstrual product ads" to move away from a feminized language of the abject feminine and toward a language of menstrual care (Bobel 2019).

\section{Blue Bloodstained Panties: A Brief Overview of Menstrual Product Advertising}

Menstruators have faced a plethora of images and ideas that treat menstruation as disgusting, contaminating, and debilitating. Menstrual product advertising has drawn upon and created this culture of negativity around menstrual experiences for decades. The phrase feminine bygiene- a relic from 1930s advertisements for birth control-itself suggests the inherent dirtiness of the female body and the relative cleanliness of the "well-managed" menstrual body (hidden, clean, out of sight), while also failing to imagine how bodies who are not feminine or female may menstruate (Fahs 2016; Tone 1996). A quick look at today's Mpads shows a range of bizarre and at times absurd paradoxes and contradictions around what menstruators should do and feel in regards to their periods.

Mpads rely centrally on shame and embarrassment to sell products, teaching the viewer that one can only properly manage menstruation by making individual decisions to reduce the possibility of disaster. That is, by buying certain brands of tampons and pads, menstruators can prevent embarrassing and shame-producing leaking, staining, and limits to their daily activities which supposedly are a result of menstruation. In short, menstrual products help to alleviate the "stain" of menstruation on women's femininity (Coutts and Berg 1993). Menstrual education products also rely on these narratives; one analysis of menstrual product booklets from 1932 to 1997 found that narratives of promoting secrecy did not change for this 50+year span (Erchull et al. 2002).

When selling single-use menstrual products, advertisers depict the menstruating body as unclean and dirty; these tactics are used to market panty liners, pads, and tampons to mainstream audiences (Berg and Coutts 1994; Kissling 2006). This is especially true in U.S. contexts, but it also has appeared in the Global South; for example, India's leading brand of single-use pads is tellingly called Whisper (Bobel 2019). Common tropes in advertising include menstrual blood depicted as "blue liquid," hyper-hygienic bleeding 
(where menstrual blood is never actually depicted), out of control bleeding where the specter of leaks and stains lurks everywhere and at all times, and narratives of intense shame and secrecy (Luke 1997). Little acknowledgment of the environmental destructiveness of single-use products is shown, thus promoting hyper-consumerism and teaching menstruators that they can solve the menstrual taboo by using disposable, single-use products and hiding their menstrual cycles altogether (Davidson 2012). Further, the ads are designed to heighten insecurities in the viewer, particularly in adolescent menstruators (Simes and Berg 2001). Mpads depict menstrual containment as only achieved through buying single-use (typically Procter and Gamble) products, through fear of menstrual contagion, and by placing the responsibility for hiding periods on individuals (Przybylo and Fahs 2018).

Further, alongside disgust narratives, women are portrayed as sporty, active, happy, and "liberated" by good/effective menstrual products (Fingerson 2012). This leaves menstruators with a variety of contradicting messages, such as: that menstruation is normal but it must be kept hidden and secret; that menstruation is a state integral to "being a woman" but that it is also a tainted femininity; that menstruation must be overcome through menstrual products which enable women to imagine themselves as active and full of "empowered" femininity; and that protection failure and incorrect product choice are the ultimate problems but freedom is achieved through the correct product choice (Raftos, Jackson, and Mannix 1998). Menstruation, then, is depicted in advertisements as the ultimate mark of shame and as the avenue to liberation via product consumption.

Ironically, at the same time, Mpads have consistently benefited from feminist advances and co-opted feminist vocabularies toward the selling of products. Sharra Vostral (2008) discusses the ways in which menstrual product companies have absorbed feminist advances toward selling their wares, such as in the 1920s as well as the 1970s and 1980s, when the feminist work of asserting bodily autonomy and not being constrained by bleeding was capitalized on, so that products were framed as having "freed the body" (Saz-Rubio and Pennock-Speck 2009, 2547). For example, in the context of 1960s civil rights and feminist struggles, menstrual products began to co-opt the language of liberation with the branding of new products such as "Newfreedom" and "Stayfree" (Vostral 2008).

This absorption of feminist discourses by menstrual product manufacturers is part of a larger ongoing phenomenon of "commodity feminism," "marketplace feminism," or "femvertising" (Goldman, Heath, and Smith 1991; Gill 2008; Heath and Potter 2005; Zeisler 2016). Scholars have argued that feminist gains are taken up, distilled, and diminished when the mainstream marketplace takes hold of them, such that larger social inequalities remain unchallenged while a veneer of progress and advancement on individualistic and consumerist terms is provided (Banet-Weiser and Portwood-Stacer 2017; Zeisler 2016). In terms of advertising, as Andi Zeisler argues, feminism tends 
to be framed less as "a set of values, ethics, and politics, [and more as] an assessment of whether or not a product is worthy of consumption" (2016, 32). Similarly, the Mpads we consider in this chapter absorb feminist discourses as a means to shake off the tawdry, retrograde, sexist ideas of history and to step into a new "liberated" era of empowered bleeding that can best sell their products.

\section{Empowered Bleeders: The "Liberated” Era of Menstrual Product Advertising}

While both large scale and small-scale feminist-oriented companies (such as Lunapads) seek to shed the sexism of the past toward reenvisioning a newly liberated menstrual subject, we will focus on two types of new Mpads emerging from the big players of menstrual products, such as Kotex, Always, and Bodyform/Libresse. As mentioned, we focus on ads put forward by large Western corporations that have profited and continue to profit from menstrual shaming, even while also profiting from co-opting feminist discourses and political advances. We group our analysis into two trends we see as arising in contemporary menstrual advertising, and draw on several examples to discuss how these trends, while at first glance conveying an "empowered" approach to menstruating, continue to sneak in negative and limiting ideas around who menstruators are and what they can do.

The first trend in recent Mpads we consider involves a model that seeks to create distance from past tendencies of menstrual advertising by a direct and narrated positioning of a liberated, implicitly feminist, and explicitly empowered bleeder. We call this form of menstrual product advertising the "peppy performance" model since it works hard to put forward a peppy performance of happy bleeding. The second form of menstrual product advertising we elaborate on involves the demonstration of empowerment through the envisioning of femininity as a site of sportiness, toughness, and ability; this model we identify as the "fit bleeding" model. In what follows we examine each of these approaches to envisioning the newly liberated menstruator and menstrual product brand and the extent to which these approaches revitalize tropes around bleeding and menstrual product advertising.

In the "peppy performance" approach to Mpads, sarcastic and humorous approaches to various aspects of the commercialized experience of menstruation are honed through a knowing feminist discourse that is informed by activists' "radical menstrual humor" (Bobel 2010, 127-32). One example of this approach is "Reality Check," which advertises a line of "new" menstrual products named "U" by Kotex. Owned by Kimberly-Clark (the producer of Kleenex), Kotex launched in 1920 drawing on its stock of excess cellucotton bandages after the first world war, with a successful advertising campaign launched in 1921 in Ladies' Home Journal (Vostral 2008, 65). U by Kotex was in turn launched in 2009 and is directed at young adult menstruators 
aged 14-21 (Newman 2010). In a series of ads spanning several years, a knowing tone of ridicule is developed by the narrators, one that seeks to distance $\mathrm{U}$ by Kotex from other menstrual products through establishing a knowingly liberated and skeptical menstruating subject.

For instance, in "Reality Check" (2013), a twenty-something white, apparently middle class cisgender woman pokes fun at the euphemistic tradition of Mpads. She asks herself, "How do I feel about my period?" and answers this question by saying "I love it. I want to hold really soft things like my cat; it makes me feel really pure. Sometimes I just want to run on the beach. I like to twirl, maybe in slow motion, and I do it in my white spandex. And usually by the third day I really just want to dance." Throughout this narration clips are shown from other Kotex commercials that feature pink butterflies, women running on beaches or doing yoga in white clothing while holding a red ball. The ad ends with the narrator poking fun at the biggest euphemism in Mpads - the blue liquid - by saying "the ads on TV are really helpful cause they use that blue liquid and I'm like oh that's what's supposed to happen." As the commercial concludes, Kotex asks us "Why are tampon ads so ridiculous?" proceeding to propel us "to break the cycle" and use U by Kotex. Through referencing knowledge about the ridiculousness of menstrual product advertising, Kotex strives to situate U by Kotex as an elevated, "with it" line of menstrual products that speak for and to a newly empowered feminine subject. The message resonates as knowingly enlightened and "empowered" while Kotex washes its hands of its legacy as a producer of harmful discourses around menstrual blood and women's bodies throughout its nearly 100-year long history of Mpad production. In this sense, "Reality Check" subtly places the blame for retrograde ideas around bleeding on menstruators themselves while undertaking the peppy performative work necessary to distance itself from its own role in menstrual shame.

Another form of peppy performance is visible in the Mpad advertising around the HelloFlo Period Starter Kit. HelloFlo is an e-commerce company "focused on providing products, content and services for women and girls through every life stage" (helloflo, "FAQs" 2018). The HelloFlo website strives to include a greater variety of individuals in menstrual conversations and features posts in relation to such topics as bleeding while in a wheelchair, menstrual pain and bloating, and menstrual activism. Menstrual studies scholar Chris Bobel (2006) has argued that "menstrual product activism" of smaller companies such as Lunapads effectively directs public attention to the environmental and health hazards of menstrual product disposability, and to "the promotion of healthier, less expensive, and less resource-intensive alternatives" (331). While HelloFlo in many ways is characteristic of what Bobel outlines as "menstrual product activism," HelloFlo is also partnered with Kotex, suggesting a more insipid co-optation of menstrual product activism.

HelloFlo, in partnership with $U$ by Kotex, has created a series of three Mpads to promote the Period Starter Kit-"The Camp Gyno," "First Moon Party," and "The Period Fairy." In imaginative ways, these ads draw 
on feminist humor to sell products to young girls and their parents through reimagining the period on empowering and positive terms. The first period appears in these ads less as a "curse" than as a "red badge of courage," "cherry slush club," "blood sisterhood" and "vagical" experience. Through the Mpads, in other words, $U$ by Kotex and HelloFlo imaginatively seek to remake and rename the first period as a happy, celebratory, and above all humorously feminist experience for young feminized and feminist-attuned menstruators. For example, "The Period Fairy" features a young black girl in her quest for the "shero" that is the "period fairy." Obliterated out of history, the period fairy nonetheless has a "herstory" that is related throughout the ad. While our narrator never manages to find her, she learns that she can be her own "shero" while wearing glittery tampon earrings (a feminist staple of menstrual embrace). Along similarly inventive lines, "Camp Gyno" features a young white girl who attains power and popularity at camp after she is the first to get her period and "First Moon Party" features a young white girl with such a deep desire to get her period that she fakes it by painting rubylicious nail polish on a pad in hopes of fooling her mom and friends (see Fig. 30.1). The mother, who is not convinced since "what she thinks I wouldn't know? Periods don't have glitter in them," decides to organize a menstrual party for her daughter replete with pin the pad on the period, a uterus piñata, marshmallows dipped in a red fondue fountain, and a vagician (see Fig. 30.2).

Wildly imaginative and hilarious, these Mpads play with feminist rhetoric to reimagine the first period as fun, humorous, and ultimately positive and empowering. Yet even as they aspire to multiculturalism and diversity as well as to reimagining the period experience, the Mpads function to uphold the value of the commercialization of bleeding through selling the Period Starter Kit as (in their words) "Santa for your vagina." Mobilizing feminist language and gynocentric imagery, the ads perform a peppy commercialization of the period experience, suggesting that it is ultimately the period starter kit that can change experiences around bleeding while continuing to remain
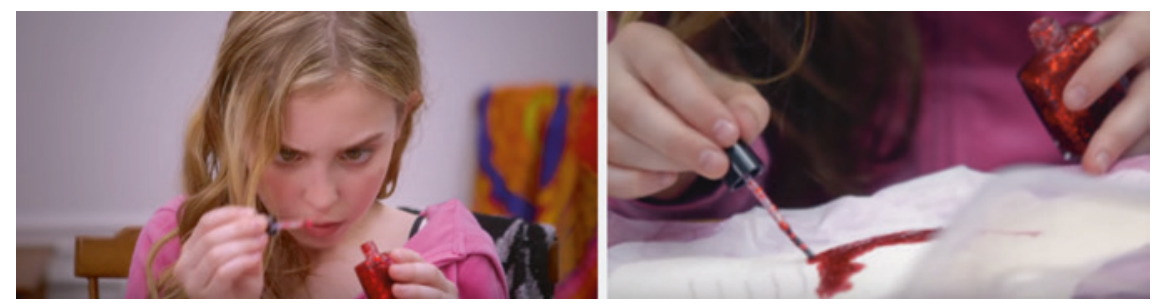

Fig. 30.1 a and b. "First Moon Party" (2014) by HelloFlo Period Starter Kit (partnered with Kotex). The film stills feature the young white girl painting rubylicious nail polish on a pad in hopes of fooling her mom and friends that she has gotten her period 

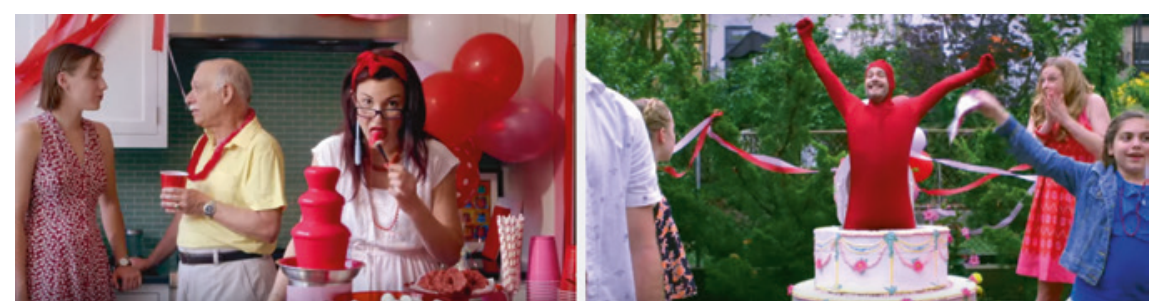

Fig. 30.2 a and b. "First Moon Party" (2014) by HelloFlo Period Starter Kit (partnered with Kotex). The film stills feature the blood-themed menstrual party the mother throws when her daughter tries to fool her that she's experiencing menarche. Notice the playful approach of the "First Moon Party" exhibited by the bleeding red fondue fountain and the menstruation-man exploding from the cake

inattentive to issues of menstrual injustice (such as uneven access to menstrual products) as well as menstrual pain, discomfort, and gender dysphoria. Also, these Mpads continue to feminize menstruation as an experience that is only pertinent to young girls who present in feminine ways, failing to imagine how variously gendered children might also experience menstruation as well as be incapable of experiencing it on liberating, empowering, or positive terms. Further, in subtle ways these Mpads continue to focus on bringing ease and positivity to the white menstrual experience as they continue to focus on white girlhood, even while including girls of color.

The second approach to "liberated" menstrual product advertising moves away from a feminized representation of period bleeding. It involves a discourse of "fit bleeding" that strives to distance itself from the feminization of menstruation and move toward a masculinizing discourse around bleeding rooted in toughness and sportiness on able-bodied terms. The bodies represented are fit, capable, thin, and non-disabled, grounded in ideals of the perfectly optimized feminine body that exists in itself as a symbol of social equality and liberation. These ads tap into decade-old discourses around situating sportiness as an aspirational mode of femininity, a desirable way to embody "being a girl." Discourses of sportiness and activeness have been rehearsed in menstrual product advertising since the early days of Mpads such as with the use of various sports including golf in the later 1920s, as well as swimming, cycling, and more recently tennis (featuring Serena Williams) (Jutel 2005; Rice 2014, 220). Promoting activity as a form of freedom from female biology and/or menstruating, advertisers have for decades relied on selling products through the trope of bodily freedom, implying that "products would free them from the bondage of female bodies and preserve femininity" (Vostral 2008, 74; Rice 2014, 220; Kissling 2006). Drawing on sports to prove the maximum protection and dynamism of a particular menstrual product brand, this tradition of ads stipulates women's and 

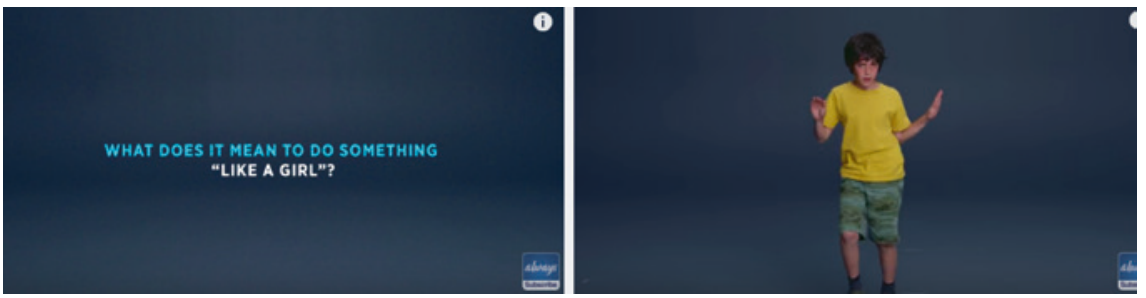

Fig. 30.3 a and b. "\#LikeAGirl" first launched by Always in 2014. The film stills feature a white young boy performing running "like a girl"

girl's sportiness as an achievement of liberation, as a demonstration of gender equality, and as an accomplishment facilitated by menstrual products themselves.

For example, “\#LikeAGirl” first launched by Always in 2014, actively distances itself from sexist notions around gender while remaining caught up in envisioning girlhood in terms of bodily capacity, ability, and sport performance. Parallel to "Reality Check" by U by Kotex, Always develops a strategy that involves distancing itself and absolving itself of responsibility for menstrual shaming, sexism, and body negativity that it has capitalized on since its introduction by Procter and Gamble in 1983. In the original "\#LikeAGirl" Mpad from 2014, a series of white and of color cisgender girls, young women, one boy, and one man are asked to perform actions such as "run like a girl," "fight like a girl," and "throw like a girl" (see Fig. 30.3). Always presents this pseudo-feminist lesson as a moment to assert that "confidence plummets during puberty" and that "Always wants to change that." Again, without providing a contextualization of the sexist, racist, and fatphobic landscape in which girls come to hate their bodies in the first place, and without taking responsibility for its role in perpetuating sexist stereotypes in the past through its advertising, Always appears here as an enlightened, pseudo-feminist company. Benefiting directly from menstrual activism and feminist involvement in shifting ideas around bodies and menstruation, Always instead presents itself as a vanguard brand at the head of the feminist struggle. In doing so, it directly co-opts feminist discourses to rebrand its previously sexist advertising.

Further, Always uses sportiness to gauge social equality, progress, and bodily empowerment. Drawing on discourses that situate sportiness as necessarily an achievement, Always denigrates so-called imagined "feminine" behaviors such as lack of strength, unsportiness, and performance failure on ableist, sexist, and implicitly cisgenderist and fatphobic terms. Failing to see how top sport performance and a "fit" body might not be a desired goal for all, Always minimizes the pain, discomfort, and dysphoria that might be associated with menstruation for many and especially for those who experience menstrual pain, menstruators with disabilities, and gender nonconforming 
persons. Eliding menstruation altogether, "\#LikeAGirl” by Always hones menstrual invisibility, making confusing connections between socialization, sexism, and periods that leave viewers unclear as to the role periods and Always are supposed to play in empowered subjecthood. If anything, "fitness" is conceived of as the ability to somehow overcome one's period and femininity with the enlightened Always brand leading the way.

The brand Libresse, going by Bodyform in the UK and other names elsewhere, is owned by the Swedish Essity. In recent years, Libresse has moved to advertising that taps more directly into the empowered and liberated rhetoric of the other ads we have been examining. "Blood" by Bodyform UK (2016) draws on a yet different visual language to portray fit bleeding and menstrual empowerment. The commercial features athletic and sporty bodies outperforming expectations of femininity through boxing, cycling, rugby, running, surfing, rock climbing, ballet, horse sword fighting, and skateboarding. The bodies are all fit, thin, and able-bodied though significantly not all white and with some gender variance, as masculine-presenting menstruators are featured in the ad (see Fig. 30.4). Here, all the bodies are shown to be bleeding due to their high sport performance-we see bleeding hands, bleeding toes, blood trickling down the face, scraped knees, et cetera. The slogan in turn reads "no blood should hold us back" and "live fearless bodyform" while an appropriated Native American "war song" plays in the background. Recasting menstruating on fit and tough terms, blood is effectively reconceived as a muscular and masculinized experience akin to other forms of high-performance bleeding. Empowerment operates here on tougher and more astutely marketable terms as menstruating is rebranded as both an experience that does not stand in the way of optimal performance as well as part and parcel of the dirty, gritty life that characterizes excelling at any sport. Drawing on a masculinizing rhetoric of celebrating sport injuries and a dark, gritty, serious color scheme (see Fig. 30.4), "Blood" remakes bleeding into a heroic pursuit in a way that no other ad has managed to do. At the same time, "Blood" invites us to imagine menstrual blood as part of a life of
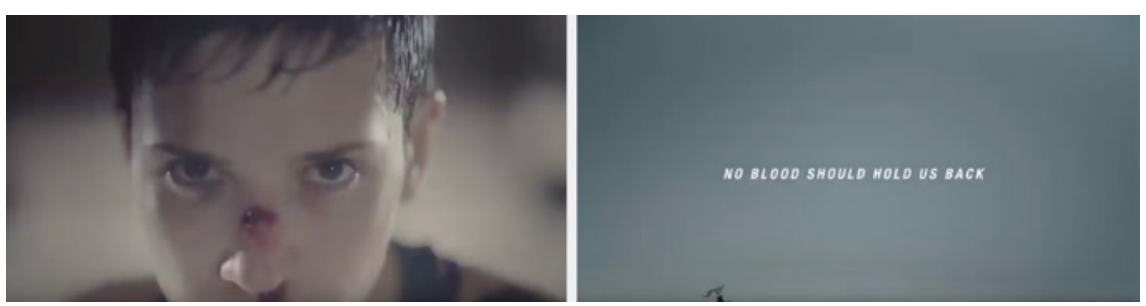

Fig. 30.4 a and b. "Blood" by Bodyform UK//Libresse (2016). The film stills feature a masculine-presenting boxer bleeding from the nose after a boxing match as an example of how "no blood should hold us back" whether it be menstrual or nonmenstrual blood 
fitness on thin and largely able-bodied terms. Also, even as multiple forms of bleeding are shown on heroic terms toward selling menstrual products, menstrual blood or bleeding is nowhere visually indexed in this ad. Thus, even while "Blood" argues for the similarity between "all blood" in its message, it refrains from doing so in its visuals.

In various ways, the Mpads we have explored foreground a new era of menstrual product advertising and aim to speak to an empowered menstruator who, for the most part, is enticed to envision menstruation on positive, celebratory, and liberated terms. Always, U by Kotex, and Libresse/ Bodyform, position themselves as leaders of this new vanguard of empowered menstrual positivity, tending to critique and distance themselves from their role in upholding and creating sexist menstrual shaming discourses. At the same time, the "new" empowered menstrual subject continues to be envisioned on cisgenderist terms often directly rooted in an ableist approach to bodily performance and sportiness. Not only are disabled bodies not portrayed, ableism is imbued in the fit performance of an achievement-oriented sporty femininity that is masculine, rough, and above all imagined as socially equal to men through the disavowal of continuing socially and capitalistically sanctioned misogynism and inequality. Drawing on Sarah Banet-Weiser and Laura Portwood-Stacer's (2017) discussion of commodity feminism, these advertisements "[seem] to explicitly recognize that inequality exists while stopping short of recognizing, naming, or disrupting the political economic conditions that allow that inequality to be profitable" (886). In conceiving of menstruation on predominately celebratory lines, an "empowered" menstruating subject is developed, one that is girly and peppy, feminine yet sporty, and that is distanced from menstrual pain, discomfort, and gender dysphoria. While reinvisioning menstruation is a vital aspect of challenging sexism, these ads co-opt feminist discourse and are strategically ignorant of the pernicious roles that capitalism itself plays in the menstrual experience. These Mpads tout a new "empowered," "liberated," and "reflexive" approach to menstrual products that claims to be critical of itself and co-opts the language of menstrual and bodily positivity in a thinned way and ultimately toward pushing consumer capitalist goals of selling menstrual gear. Even more troublingly, the "empowered" message sells a happy and mood-controlled menstrual experience that foregoes questions of pain and menstrual justice.

\section{Cranky Menstruators: Beyond Body and Menstrual Positivity}

In many ways, some of the Mpads we reviewed push the envelope of advertising, dismantle harmful ideas around menstruation, and challenge sexist discourses around body shaming. Yet they do so not because Kotex, Always, or Bodyform are themselves liberating products to use, but rather because feminist and menstrual activisms have paved the way for a rhetoric of body positivity and menstrual positivity to take hold. Body positivity draws on decade long traditions that originate in Black Power, disability justice, transgender 
organizing, and fat activism. Maxine Leeds Craig (2002) discusses how the politics of Black Power in the sixties and seventies were firmly grounded in aesthetic styles that established that "black is beautiful." Remaking the very concept of beauty, black activists and thinkers of the era laid claim to self-love in a black-loathing U.S. context. This in turn expanded the possibilities of representation in advertising "to include some black women" (108), with, for example, the first black woman appearing in an Mpad in 1962 in Ebony magazine. Further, "[ $\mathrm{t}]$ he message embedded in the styles and practices [of the era] was throw off the old and love yourself. Self-love became understood as a political act" (Craig 96; also see Hobson 2016). In other words, black activism conceptualized body positivity and self-love as a deeply political terrain central to revolutionary struggle.

Yet self-love and body positivity are necessarily transformed in the hands of advertisers. Relying on activist body work, ad campaigns draw on the cultural and political resources of feminism and other social movements both indirectly and directly, such as for example with the hiring of feminist experts as consultants for ad campaigns as with Dove's Real Beauty Campaigns. Rosalind Gill and Ana Sofia Elias (2014) argue that "love your body" discourses in advertising contain elements of psychic regulation since a new disciplinary norm has emerged that requires self body-love for feminine-presenting subjects in particular. It is ironic to think that just as a greater variety of bodies are represented in advertising, the spectrum of acceptable moods and dispositions toward one's body is narrowing.

"Love your body" themes in advertising, Gill and Elias outline, are forms of "emotional capitalism" (Illouz 2007), and while they portray bodies on more positive terms, this is often simultaneously undermined by an imperative to love one's body without a full consideration of social contexts of misogynism, transphobia, fatphobia, ableism, and ageism. Rather, an individualized responsibility emerges to overcome social hatred within oneself, to change one's relationship with oneself and one's body because one's "relationship to the self has gone bad or been broken" (Gill and Elias 2014, 181). Redefined beauty and abstract love are held open as possibilities to consumers even as political struggle and collective organizing that might challenge capitalistic self-realization are not. As such, a necessarily shallow version of body positivity emerges, one that reroutes its original politicized energies toward consumer culture and individualized "overcoming."

In this section, we argue that body and menstrual positivity need to be complimented by bodily and menstrual crankiness. We hold that while bodily celebration, including menstrual positivity, is an important component of the feminist landscape today, it is equally important to retain a cranky approach to the body and embodiment-one attuned to pain, leaking, trauma, discomfort, and dysphoria. A cranky approach to menstruation, in particular, asks that we take stock of the uncomfortable and dissident feelings that are part and parcel of the menstrual experience as much as the ads we reviewed suggest otherwise. Rather than celebrating menstruation and advances in 
menstrual ads, we call for a cranky approach to bleeding that is invested in social justice, demands access to menstrual products for all, and that is alerted to the pain and discomfort involved in bleeding.

Reconceiving of menstruation on positive terms has been central to shifting women and menstruators' embodied experiences of bleeding. Menstrual bleeding has a long history of being stipulated on profoundly negative terms and has been historically conceived of as a pathology, debility, and biological proof of gendered inferiority (Steinem 1978; Aristotle in Dean-Jones 1994; Martin 2001; Vostral 2008). Menstrual activists and feminists have led the way in challenging such negative understandings of menstruation through art, zines, protest signage, performance, and online discourse (Bobel 2006, 2010; Clemmer 2017; Fahs 2016; Truax 2017). At the same time, menstruation can be a difficult and taxing embodied experience entwined with pain (such as dysmenorrhea and endometriosis), discomfort, dips in mental health, and it can shore up gender dysphoria for transmasculine, genderqueer, and gender variant bleeders (Chrisler et al. 2016; Fahs 2016). While menstrual pain is routinely denied the status of "real" pain, studies suggest that up to $85 \%$ of menstruators experience pain, sometimes as serious as the pain experienced during a heart attack (Przybylo and Fahs 2018; Fenton 2016; Jones 2016; Balbi et al. 2000; Banikarim, Chcacko, and Kelder 2001; Grandi et al. 2012; Ju, Jones, and Mishra 2014). Though some report positive experiences with menstruation, overwhelmingly, menstruating women report menstrual negativity (likely because they exist in a culture of shaming menstruation), including emotions like shame, disgust, embarrassment, and horror (McPherson and Korfine 2004; Roberts 2004). These feelings are at once somatic, psychic, and rooted in social stigma. The first period is also often experienced as traumatic in itself, and is characterized by distress, shock, and dread (Rice 2014, 227-28).

Periods can also trigger gender dysphoria, or the distress associated with one's gender not aligning with one's body appearance (Bell 2017; Reading 2014). Notably, advertising for menstrual products can itself have a disorienting and triggering effect on transmasculine and genderqueer bleeders, since it "enforces the otherness of [one's] period" and one can "feel mocked by the celebratory ads and the excited-looking packaging" (Zulch 2017). Women who do not bleed, including postmenopausal women, post-hysterectomy women, and transgender women, are in turn publicly left out of conceptualizations of womanhood through Mpads that serve to draw up the contours of "womanhood" in terms of whether one menstruates or not (Bobel 2010). Further, most MPads visually exclude transgender women from the menstrual celebrations of womanhood. Alongside blatantly transexclusionary advertising, the effusively celebratory tone common among the Mpads we examined has a deleterious effect on many bleeders who experience mental unwellness and physical pain during their periods. In this regard, even while an overly celebratory and peppy tone of menstrual product advertising seems to advocate for a more positive approach to the menstruating body, it fails many types of bodies including trans, genderqueer, gender variant 
folks, menstruators with disabilities, and those who experience pain and dips in mental wellness during their periods. We thus see the need to develop an approach to periods that creates space for the difficult aspects of bleeding and fosters a "cranky" approach to menstruation.

We see menstrual crankiness as an approach to bleeding that hones and acknowledges the negative, troubling, painful, and traumatic aspects of the period experience. First, this approach challenges the overwhelming social call to be happy and positive, including in regards to bleeding. Sara Ahmed (2010) outlines how happiness has been used as a form of social regulation, especially in regards to oppressed people, so that happiness and positivity emerge as "not so much a right as a responsibility. We have a responsibility for our own happiness insofar as promoting our own happiness is what enables us to increase other people's happiness" (9; see also Frye 1983, 2-3). Positivity has emerged as an American paradigm rooted in U.S. exceptionalism and a pull yourself up by the bootstraps orientation based in the false idea that "success happens to good people and failure is just a consequence of a bad attitude" (Halberstam 2011; see also Ehrenreich 2009). In relation to menstruation this is rooted in the idea that positive thinking can positively affect the menstrual experience and wish away bodily trauma and pain. It thus deduces that one's menstrual experience-whether it is happy or difficult-is based on one's psychology and "outlook" rather than in the materialities and structural inequalities of pain and trauma.

A cranky approach to menstruation asks that we question broader projects around body positivity and menstrual positivity and the ways in which they have been co-opted. As Jack Halberstam (2011) writes, crankiness, like other "negative affects [...] poke[s] holes in the toxic positionality of contemporary life" (3). In honing a cranky approach to menstruation, we are interested in challenging the overwhelming call to "love our periods" and "love our bodies" even while the "our" of these statements is always more available to some more so than others. The cranky menstruator is positioned in opposition to these celebratory scripts, understanding them as just another way to milk menstruators' pockets for money. In this sense, the cranky menstruator is, drawing again on Ahmed (2010), a "troublemaker [who] might be trouble because [they get] in the way of the happiness of others" by refusing to make bleeding palatable and celebratory (60). Like Ahmed's killjoy who "might bring others down [...] by talking about unhappy topics such as sexism" the cranky menstruator is cranky about menstrual pain, menstruatory exclusion, menstrual capitalism, and uneven access to menstrual products (66). Ahmed argues that "happiness provides as it were a cover, a way of covering over what resists or is resistant to a [particular] view of the world" (83-84); we see menstrual positivity in advertising functioning in a similar way, covering up particular truths about bleeding in pursuit of a peppy, fit, and utilizable bleeding body. In this sense, crankiness is both metaphoric and embodied, grounded in a cranky approach to injustice fueled by feminist anger as well as by the material aspects of menstrual crankiness. 
Yet even as the Mpads we reviewed hold out happiness in the form of menstrual positivity to menstruating bodies, they implicitly draw a line as to who can share in this menstrual happiness by excluding bodies of size, masculine of centre and genderqueer bodies, transfeminine bodies, and disabled bodies from its cornucopias of menstrual celebration. Drawing on Ahmed's words, these differently menstruating bodies are "banished" from happiness in the menstrual advertising landscape, with menstrual happiness and celebration not evenly extended to all (17). Or in Halberstam's language, menstrual experiences and bodies not represented in advertisement celebrations come to form the "failed" subjects of menstruation-those who cannot, will not, or are not invited to celebrate in the blood party.

A body and menstrual positivity that wants to guarantee that we love our periods and bodies flattens and disregards some of the more difficult and troubling aspects of bleeding. Using crankiness to critique the co-optation and wholesale application of menstrual positivity creates space to recognize the realness of menstrual pain and menstruation-related trauma as well as the ways in which menstruation can actually stimulate bodily hatred and loathing rather than bodily love. Allowing for a recognition of the self-loathing that bleeding can ignite suggests that working toward body-love and menstrual-love are not always practical, feasible, or even preferred models for coping with periods. Rather, body-love and menstrual-love, are conveniently utilizable by capitalist schemas of round-the-month productivity that encourage menstruators to "overcome" pain and trauma at all costs toward better serving the labor force and ideals of a contained, non-leaky, fit, and non-disabled body. A cranky approach to menstruation also challenges the idea of the celebrated "fit" bleeder proffered in many Mpads. A menstrual crankiness thus is cranky about a model of bleeding that adheres to a fitness paradigm and represents particular bodies toward selling the period as something that can and must be overcome. Instead, menstrual crankiness recognizes that period pain can prevent sport performance, that periods as they relate to dysphoria, trauma, and depression, can and do incite anger, discontent, disavowal, and dissonance rather than happy positive feelings.

Finally, a cranky approach to menstruation also suggests that we need to be very, very cranky about how menstrual products advertise themselves as "liberated" and their menstrual gear as "liberating" while menstruators in North America and around the world are not provided access to menstrual supplies such as tampons, pads, cups, and pain killers. With prices of menstrual products increasing annually, and with taxes placed on menstrual products that mark them as an "inessential" commodities (though this is starting to change), access to menstrual products operates as a capitalist privilege aligned with class privilege, white privilege, and first world privilege. Groups in vulnerable situations such as incarcerated people, homeless people, and even hospitalized people are routinely denied and restricted access to this basic human necessity, just as menstruators in the Global South are portrayed as "uncivilized" for using rags, bark, or other non-commercial materials for 
managing their menstrual cycles (Bobel 2019). If menstrual commodities, as Mpads have suggested for decades, are emblems of "empowerment" that make civic participation more possible for menstruators through containing bleeding, access to menstrual products and recognition that many ways of managing menstruation are possible, needs to be extended far and wide. Activists have been getting cranky about this throughout the last decade, as is demonstrated by efforts ranging from eliminating the "tampon tax" (Crawford and Spivack 2017), to providing menstrual products to incarcerated women (Marusic 2016; White 2018), to questioning the (largely white) efforts to "give" menstrual products to women and girls in the Global South (Bobel 2019).

A cranky approach to menstruation thus needs to be committed to forgoing menstrual celebration in favor of greater access to menstrual supplies and products and a broader challenging of consumer capitalism. Menstrual activism itself must continue its cranky quest to move beyond products-as-the-end-goal and instead look deeper into the root structures of why Mpads exist and why they "sell" menstruators their own empowerment through highly problematic frameworks of narrow femininity. And finally, a radical analysis of why women lack such access must underlie all efforts to disseminate menstrual products on a wider scale; to ignore the bigger stories surrounding the traveling, marketing, and usage of menstrual products reduces the potential justice implications of radical menstrual activist work. Such activist work seeks to not only transform the way people "manage" their periods, but also to link up with other social justice movements that think and work together on ways to reduce stigma, improve the material conditions of people's lives, and transform thinking about bodies and embodiment.

\section{REFERENCES}

Ahmed, Sara. 2010. The Promise of Happiness. Durham, NC: Duke University Press.

Balbi, C., R. Musone, A. Menditto, L. Di Prisco, E. Cassese, M. D’Ajello, D. Ambriosio, and A. Cardone. 2000. "Influence of Menstrual Factors and Dietary Habits on Menstrual Pain in Adolescence Age." European Journal of Obstetrics o Gynecology and Reproductive Biology 91 (2): 143-48.

Banet-Weiser, Sarah, and Laura Portwood-Stacer. 2017. "The Traffic in Feminism: An Introduction to the Commentary and Criticism on Popular Feminism." Feminist Media Studies 17 (5): 884-88.

Banikarim, Chantay, Mariam R. Chcacko, and Steve H. Kelder. 2001. "Prevalence and Impact of Dysmernorrhea on Hispanic Female Adolescents." Archives of Pediatrics and Adolescent Medicine 154 (12): 1226-29.

Bell, Jen. 2017. “Gender Dysphoria and Your Cycle.” Clued In. https://medium. com/cluedin/gender-dysphoria-and-your-cycle-5c9922bad7ef.

Berg, D. H., and L. Block Coutts. 1994. "The Extended Curse: Being a Woman Every Day." Health Care for Women International 15 (1): 11-22.

Bobel, Chris. 2006. “'Our Revolution Has Style': Contemporary Menstrual Product Activists 'Doing Feminism' in the Third Wave.” Sex Roles 54 (5-6): 331-45. 
2010. New Blood: Third Wave Feminism and the Politics of Menstruation. Camden, NJ: Rutgers University Press.

- 2019. The Managed Body: Developing Girls and Menstrual Health in the Global South. London: Palgrave.

Chrisler, Joan C., Jennifer A. Gorman, Jen Manion, Michael Murgo, Angela Barney, Alexis Adams-Clark, Jessica R. Newton, and Meaghan McGrath. 2016. "Queer Periods: Attitudes toward and Experiences with Menstruation in the Masculine of Centre and Transgender Community." Culture, Health \& Sexuality 18 (11): $1238-50$.

Clemmer, Cass. 2017. Toni the Tampon: A Period Coloring Book. New York: Bloody Queer.

Coutts, L. Block, and D. H. Berg. 1993. "The Portrayal of the Menstruating Woman in Menstrual Product Advertisements." Health Care for Women International 14 (2): 179-91.

Craig, Maxine Leeds. 2002. Ain't I a Beauty Queen? Black Women, Beauty, and the Politics of Race. New York: Oxford University Press.

Crawford, Bridget J., and Carla Spivack. 2017. "Tampon Taxes, Discrimination, and Human Rights." Wisconsin Law Review 491. http://digitalcommons.pace.edu/ lawfaculty $/ 1070 /$.

Davidson, Anna. 2012. "Narratives of Menstrual Product Consumption: Convenience, Culture, or Commoditization?” Bulletin of Science, Technology, \& Society 32 (1): 56-70.

Dean-Jones, Lesley. 1994. "Medicine: The 'Proof' of Anatomy." In Women in the Classical World, edited by Elaine Fantham, Helene Peet Foley, Natalie Boymel Kampen, Sarah B. Pomeroy, and H. A. Shapiro. 183-205. New York: Oxford University Press.

Ehrenreich, Barbara. 2009. Bright-Sided: How the Relentless Pursuit of Positive Thinking Has Undermined America. New York: Metropolitan Books.

Erchull, Mindy J., Joan C. Chrisler, Jennifer A. Gorman, and Ingrid Johnston-Robledo. 2002. "Education and Advertising: A Content Analysis of Commercially Produced Booklets about Menstruation." The Journal of Early Adolescence 22 (4): 455-74.

Fahs, Breanne. 2016. Out for Blood: Essays on Menstruation and Resistance. Albany, NY: SUNY Press.

Fenton, Siobhan. 2016. "Period Pain Is Officially as Bad as a Heart Attack-So Why Have Doctors Ignored It? The Answer Is Simple." The Independent, February 19, 2016. http://www.independent.co.uk/voices/period-pain-is-officially-as-bad-as-aheart-attack-so-why-have-doctors-ignored-it-the-answer-is-a6883831.html.

Fingerson, Laura. 2012. Girls in Power: Gender, Body, and Menstruation in Adolescence. Albany, NY: SUNY Press.

Frye, Marilyn. 1983. The Politics of Reality: Essays in Feminist Theory. Trumansburg, NY: Crossing Press.

Gill, Rosalind. 2008. "Empowerment/Sexism: Figuring Female Sexual Agency in Contemporary Advertising." Feminism and Psychology 18 (1): 35-60.

Gill, Rosalind, and Ana Sofia Elias. 2014. “'Awaken Your Incredible’: Love Your Body Discourses and Postfeminist Contradictions." International Journal of Media and Cultural Politics 10 (2): 179-88.

Goldman, Robert, Deborah Heath, and Sharon L. Smith. 1991. "Commodity Feminism." Critical Studies in Mass Communication 8: 333-51. 
Grandi, Giovanni, Serena Ferrari, Anjeza Xholli, Marianna Cannoletta, Federica Palma, Cecilia Romani, Annibale Volpe, and Angelo Cagnacci. 2012. "Prevalence of Menstrual Pain in Young Women: What is Dysmenorrhea?" Journal of Pain Research 5 (2012): 169-174.

Halberstam, Jack. 2011. The Queer Art of Failure. Durham: Duke University Press.

Heath, Joseph, and Andrew Potter. 2005. The Rebel Sell: How the Counterculture Became Consumer Culture. Chichester and Toronto: Wiley.

Helloflo. 2018. "FAQs." http://helloflo.com/faq/.

Hobson, Janell. 2016. "Black Beauty and Digital Spaces: The New Visibility Politics." Ada: A Journal of Gender, New Media, and Technology 10. http://adanewmedia. org/2016/10/issuel0-hobson/.

Illouz, Eva. 2007. Cold Intimacies: The Making of Emotional Capitalism. Cambridge: Polity.

Jones, Cara. 2016. "The Pain of Endo Existence: Toward a Feminist Disability Studies Reading of Endometreosis." Hypatia 31 (3): 554-71.

Ju, Hong, Mark Jones, and Gita Mishra. 2014. "The Prevalence and Risk Factors of Dysmenorrhea." Epidemiologic reviews 36 (1): 104-13.

Jutel, Annemarie. 2005. "Cursed or Carefree? Menstrual Product Advertising and the Sportswoman." In Sport, Culture, and Advertising: Identities, Commodities and the Politics of Representation, edited by Steven J. Jackson and David L. Andrews, 21326. London: Routledge.

Kissling, E. 2002. "On the Rag on Screen: Menarche in Film and Television." Sex Roles 46 (1-2): 5-12.

- 2006. Capitalizing the Curse: The Business of Menstruation. Boulder: Lynne Rienner.

Luke, Haida. 1997. “The Gendered Discourses of Menstruation.” Social Alternatives 16 (1): 28-30.

Martin, Emily. 2001. The Woman in the Body: A Cultural Analysis of Reproduction. Boston: Beacon Press.

Marusic, Kristina. 2016. “The Sickening Truth about What It's Like to Get Your Period in Prison." Women's Health. July 7, 2016. http://www.womenshealthmag. com/life/women-jail-periods.

McPherson, Marianne E., and Lauren Korfine. 2004. "Menstruation across Time: Menarche, Menstrual Attitudes, Experiences, and Behaviors." Women's Health Issues 14 (6): 193-200.

Newman, Adam Andrew. 2010. "Rebelling against the Commonly Evasive Feminine Care Ad." The New York Times, March 15, 2010. http://www.nytimes. com/2010/03/16/business/media/16adco.html.

Przybylo, Ela, and Breanne Fahs. 2018. "Feels and Flows: On the Realness of Menstrual Pain and Cripping Menstrual Chronicity." Feminist Formations 30 (1): 206-29.

Raftos, Maree, Debra Jackson, and Judy Mannix. 1998. "Idealised Versus Tainted Femininity: Discourses of the Menstrual Experience in Australian Magazines That Target Young Women.” Nursing Inquiry 5 (3): 174-86.

Reading, Wiley. 2014. "My Period and Me: A Trans Guy's Guide to Menstruation." Everyday Feminism. https://everydayfeminism.com/2014/11/ trans-guys-guide-menstruation/.

Rice, Carla. 2014. Becoming Women: The Embodied Self in Image Culture. Toronto: University of Toronto Press. 
Roberts, Tomi-Ann. 2004. "Female Trouble: The Menstrual Self-Evaluation Scale and Women's Self-Objectification.” Psychology of Women Quarterly 28 (1): 22-26.

Rosewarne, Lauren. 2012. Periods in Pop Culture: Menstruation in Film and Television. New York: Lexington Books.

Ross, Loretta, Elena GutiŽrrez, Marlene Gerber, and Jael Silliman. 2016. Undivided Rights: Women of Color Organizing for Reproductive Justice. Chicago: Haymarket Books.

Saz-Rubio, Del, Ma Milagros, and Barry Pennock-Speck. 2009. "Constructing Female Identities Through Feminine Hygiene TV Commercials." Journal of Pragmatics 41 (12): 2535-2556.

Simes, Mika R., and D. H. Berg. 2001. "Surreptitious Learning: Menarche and Menstrual Product Advertisements." Health Care for Women International 22 (5): 455-69.

Steinem, Gloria. 1978. "If Men Could Menstruate: A Political Fantasy." Ms. Magazine: 110.

Thornton, Leslie-Jean. 2013. “'Time of the Month' on Twitter: Taboo, Stereotype and Bonding in a No-Holds-Barred Public Arena." Sex Roles 68 (1-2): 41-54.

Tone, Andrea. 1996. "Contraceptive Consumers: Gender and the Political Economy of Birth Control in the 1930s." Journal of Social History 29 (3): 485-506.

Truax, Raegan. 2017. "Sloughing." https://raegantruax.com/ durational-performances/sloughing/.

Vostral, Sharra L. 2008. Under Wraps: A History of Menstrual Hygiene Technology. Lanham, MD: Lexington Books.

White, Kaila. 2018. "Arizona Prisons Will Now Give Female Inmates Free Tampons." Arizona Central. https://www.azcentral.com/story/news/politics/legislature/2018/02/21/arizona-prisons-give-free-tampons-femaleinmates/361075002/.

Winkler, Inga T., and Virginia Roaf. 2014. "Taking the Bloody Linen out of the Closet: Menstrual Hygiene as a Priority for Achieving Gender Equality." Cardozo Journal of Law and Gender 21: 1-37.

Zeisler, Andi. 2016. We Were Feminists Once: From Riot Grrrl to CoverGirl®, the Buying and Selling of a Political Movement. New York: PublicAffairs.

Zulch, Sebastian. 2017. "How Having a Period Negatively Impacts My Mental Health." Helloflo. http://helloflo.com/period-negatively-impacts-mental-health/. 
Open Access This chapter is licensed under the terms of the Creative Commons Attribution 4.0 International License (http://creativecommons.org/licenses/ by $/ 4.0 /)$, which permits use, sharing, adaptation, distribution and reproduction in any medium or format, as long as you give appropriate credit to the original author(s) and the source, provide a link to the Creative Commons license and indicate if changes were made.

The images or other third party material in this chapter are included in the chapter's Creative Commons license, unless indicated otherwise in a credit line to the material. If material is not included in the chapter's Creative Commons license and your intended use is not permitted by statutory regulation or exceeds the permitted use, you will need to obtain permission directly from the copyright holder. 